\title{
Review: Nutrient requirements of the modern high-producing lactating sow, with an emphasis on amino acid requirements
}

\author{
M. D. Tokach $^{1 \dagger} \odot$, M. B. Menegat ${ }^{2}$, K. M. Gourley ${ }^{1}$ and R. D. Goodband ${ }^{1}$ \\ ${ }^{1}$ Department of Animal Sciences and Industry, College of Agriculture, Kansas State University, 1424 Claflin Road, 66506, Manhattan, Kansas, USA; ${ }^{2}$ Department of \\ Diagnostic Medicine/Pathobiology, College of Veterinary Medicine, Kansas State University, 1800 Denison Avenue, 66506, Manhattan, Kansas, USA
}

(Received 14 March 2019; Accepted 29 April 2019; First published online 14 June 2019)

\begin{abstract}
Sow productivity improvements continue to increase metabolic demands during lactation. During the peripartum period, energy requirements increase by $60 \%$, and amino acid needs increase by $150 \%$. As litter size has increased, research on peripartum sows has focused on increasing birth weight, shortening farrowing duration to reduce stillbirths and improving colostrum composition and yield. Dietary fibre can provide short-chain fatty acids to serve as an energy source for the uterus prior to farrowing; however, fat and glucose appear to be the main energy sources used by the uterus during farrowing. Colostrum immunoglobulin $G$ concentration can be improved by increasing energy and amino acid availability prior to farrowing; however, the influence of nutrient intake on colostrum yield is unequivocal. As sows transition to the lactation period, nutrient requirements increase with milk production demands to support large, fast-growing litters. The adoption of automated feed delivery systems has increased feed supply and intake of lactating sows; however, sows still cannot consume enough feed to meet energy and amino acid requirements during lactation. Thus, sows typically catabolise body fat and protein to meet the needs for milk production. The addition of energy sources to lactation diets increases energy intake and energy output in milk, leading to a reduction in BW loss and an improvement in litter growth rate. The supply of dietary amino acids and CP close to the requirements improves milk protein output and reduces muscle protein mobilisation. The amino acid requirements of lactating sows are variable as a consequence of the dynamic body tissue mobilisation during lactation; however, lysine (Lys) is consistently the first-limiting amino acid. A regression equation using published data on Lys requirement of lactating sows predicted a requirement of $27 \mathrm{~g} /$ day of digestible Lys intake for each $1 \mathrm{~kg}$ of litter growth, and $13 \mathrm{~g} /$ day of Lys mobilisation from body protein reserves. Increases in dietary amino acids reduce protein catabolism, which historically leads to improvements in subsequent reproductive performance. Although the connection between lactation catabolism and subsequent reproduction remains a dogma, recent literature with high-producing sows is not as clear on this response. Many practical aspects of meeting the nutrient requirements of lactating sows have not changed. Sows with large litters should approach farrowing without excess fat reserves (e.g. $<18 \mathrm{~mm}$ backfat thickness), be fed ad libitum from farrowing to weaning, be housed in a thermoneutral environment and have their skin wetted to remove excess heat when exposed to high temperatures.
\end{abstract}

Keywords: amino acid, colostrum, energy, litter size, pig

\section{Implication}

Sow productivity has increased dramatically in the last decade. With improved productivity, requirements for energy and amino acids increase during lactation. To meet these needs, sows should be in proper body condition before farrowing to encourage high feed intake, and provided full access to feed in the few days before and during lactation. Diets should contain high-energy, low-fibre ingredients to maximise energy intake, and formulated with sufficient amino acid levels to meet the demands for milk production

\footnotetext{
${ }^{\dagger}$ E-mail: Mtokach@ksu.edu
}

and minimise tissue catabolism. Today's sows are resilient and, with proper nutrient intake, can withstand the rigorous demands of increased productivity.

\section{Introduction}

Genetic selection and improvements in health, management and nutrition have led to unprecedented levels of sow productivity. In 2016, pigs weaned per sow per year averaged 25.7 in the United States, with an even higher productivity in the major pork production countries in Europe, ranging 


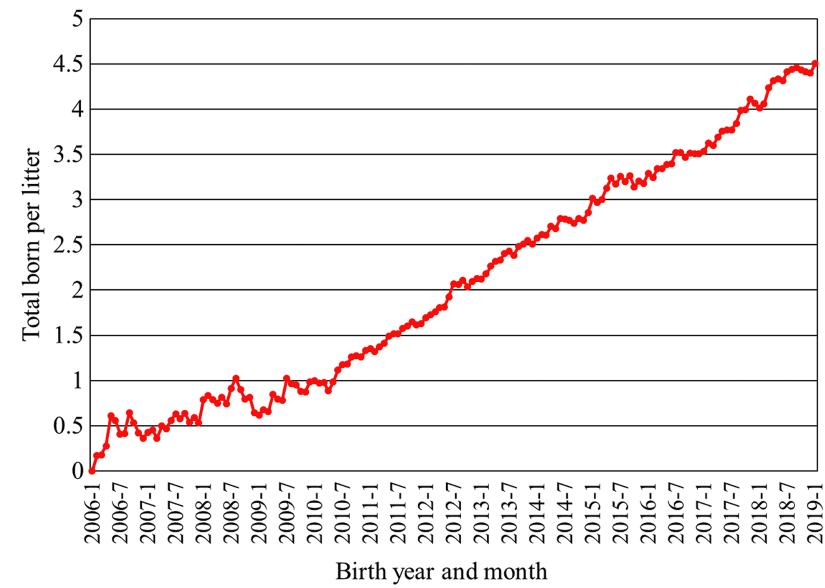

Figure 1 Genetic trend for total pigs born per litter at the nucleus level from Genus PIC (M. Culbertson, personal communications, 12 February 2019).

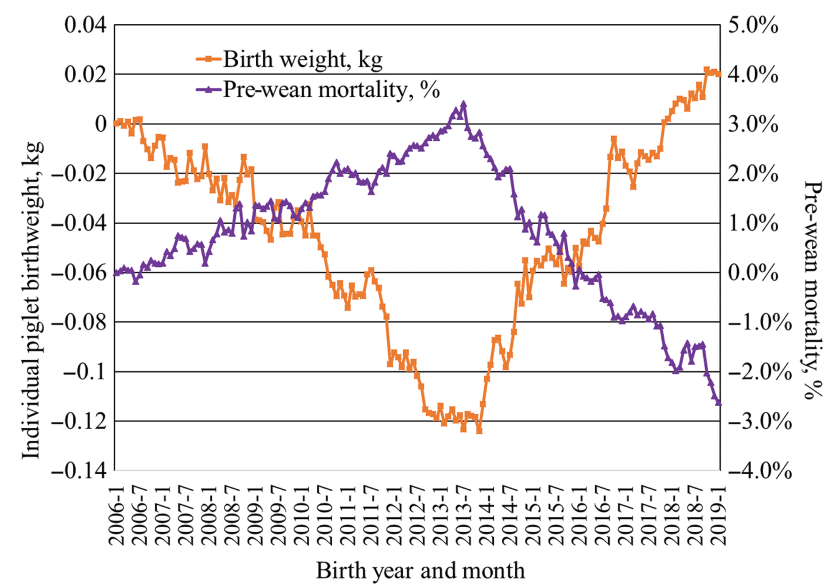

Figure 2 Genetic trend for individual pig birthweight and pre-wean mortality from Genus PIC (M. Culbertson, personal communications, 12 February 2019).

from 27.0 in Spain to 32.1 in Denmark (Agriculture and Horticulture Development Board, 2017).

Much of the increase in pigs weaned per sow has been a result of increased litter size. An increased use of genomics has accelerated the rate of progress in recent years. Data from Genus PIC illustrate the speed of change. From 2006 to 2019 , the genetic trend at the nucleus level for total pigs born increased by approximately 0.334 pig per year, or an increase by 4.5 pigs per litter over the 13-year period (Figure 1). Initially, this led to a decrease in individual pig birth weight with average birth weight decreasing by approximately $120 \mathrm{~g}$ from 2006 to 2013 with a concomitant increase in pre-weaning mortality (Figure 2). After changing the selection criteria to offset this trend in 2013, the decrease was quickly reversed. Within 6 years, the previous loss in average birth weight was recovered, and in fact, the average birth weight was $20 \mathrm{~g}$ greater in 2019 than reported in 2006 while maintaining a steady increase in total born per litter. Because of heavier birth weights, pre-weaning mortality also decreased almost 6 percentage units from the high in 2013.
The improvements in reproductive performance increase metabolic demands on the sow during gestation and lactation. Today's modern genotype females are also faster-growing and have less adipose tissue than their predecessors. In commercial production, it is not uncommon to see gilt tenth rib fat depth at farrowing average $16 \mathrm{~mm}$ and parity 2 and older sows having fat depth ranging from 12 to $16 \mathrm{~mm}$ (Kim et al., 2015; Thomas et al., 2018). These changes in body composition and reproductive performance alter nutrient requirements during gestation and lactation. Increases in litter size increase total fetal growth in late gestation, farrowing duration, colostrum needs and milk production. In this review, the nutrient demands for these biological processes are discussed, dividing the sections into the peripartum and lactation periods and the unique requirements during each period.

\section{Peripartum transition period}

While several studies have been conducted to evaluate changing nutrient requirements in late gestation (day 90 to parturition), few studies have focused on the days immediately prior to parturition. The transition period has been loosely defined as the last 10 days of gestation to the first 10 days of lactation (Theil, 2015). During the peripartum transition period, a rapid shift in nutrient requirements and nutrient partitioning occurs due to an exponential increase in fetal and mammary growth, uterine components and colostrum synthesis (Feyera and Theil, 2017). Typically, sows are limit-fed a gestation diet, then receive a set amount of lactation feed for 2 to 3 days prior to farrowing. The lactation diet is a higher lysine (Lys), higher energy diet than the gestation diet. The change from lower Lys limit-fed gestation diet to a nutrient-dense lactation diet can be met with metabolic challenges as the sow has to rapidly adapt to a new diet composition. It is important to minimise this rapid shift in nutrients at the time of parturition to avoid a negative impact on parturition and lactation performance (Martineau et al., 2013). The goal of the transition period should be to meet the changing requirements for fetal and mammary tissue growth, prepare the sow for the upcoming lactation demand and supply nutrients during parturition for maximum piglet survival at birth. Another critical activity in the peripartum transition period is colostrum production, which is estimated to begin 2 to 3 days before the onset of parturition (Devillers et al., 2004).

\section{Transition period feeding and farrowing duration}

Parturition is an energy-demanding process. As litter size continues to increase, there is also an increase in farrowing duration. A normal birthing interval is 15 to $20 \mathrm{~min}$, which could lead to a 300-min farrowing duration for a litter of 15 piglets. Several factors have been associated with an increase in farrowing duration, including sow backfat $>17 \mathrm{~mm}$ at farrowing (Oliviero et al., 2010) and increased litter size (van Dijk et al., 2005). Recently, Feyera et al. (2018) observed that farrowing duration is reduced if sows have access to feed and eat at 
(a)

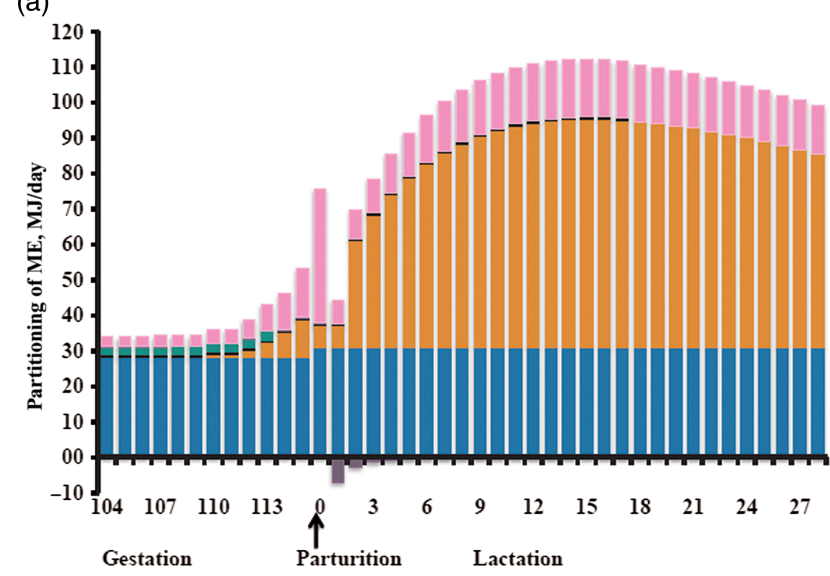

(b)

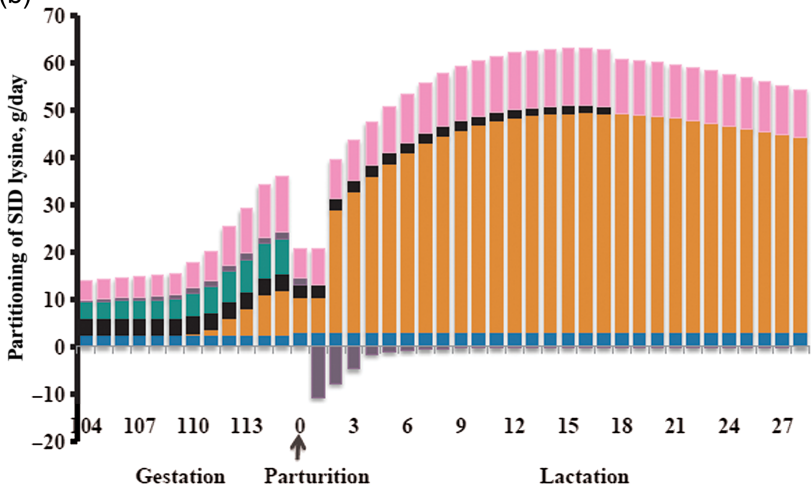

Figure 3 Calculated metabolisable energy (ME; panel a) and standardized ileal digestible (SID) lysine (panel b) requirements for maintenance (blue bars), colostrum/milk production (orange bars), mammary growth (black bars), fetal growth (green bars), uterine components (purple bars) and additional heat loss for energy or oxidation/transamination or amino acids (pink bars) in sows during transition and lactation. (Reprinted from Livestock Science, 201, Feyera and Theil, Energy and lysine requirements and balances of sows during transition and lactation: A factorial approach, 50-57, 2017, with permission from Elsevier.)

least $3 \mathrm{~h}$ before farrowing, hypothesising that this is due to a greater availability of energy. However, Cools et al. (2014) fed a lactation diet ad libitum starting on day 105 of gestation and did not affect farrowing duration. This study had fewer total born (11 pigs), which may explain the reason why no differences were observed. Several other nutritional strategies during the transition period have been investigated for their effects on farrowing duration. Reduced farrowing duration was observed with added phytase (Manu et al., 2018) or soluble fibre sources (Theil et al., 2014), but not with creatine (Vallet et al., 2013) or a dietary nitrate supplement (van den Bosch et al., 2019). Interestingly, Feyera et al. (2018) observed that during late gestation the uterus partially satisfies its energy demand using acetate and butyrate from dietary fibre inclusion. Conversely, during farrowing, these short-chain fatty acids are not extracted by the uterus, but rather triglycerides and glucose are used as the energy source. Therefore, while short-chain fatty acids may be used by the uterus in late gestation, feeding a diet containing increased triglycerides and glucose a day prior to parturition could supply the readily absorbed energy required by the uterus during parturition, which could positively benefit uterine contractions and reduce farrowing duration and stillbirth rate.

\section{Energy requirements in the peripartum transition period}

Dietary energy requirements during gestation are derived from body maintenance, growth of conceptus and maternal demands from the mammary and uterus. These requirements will also depend on sow BW, parity and environmental conditions (Trottier et al., 2014). Of particular interest in the transition period are the requirements to support an exponential growth rate of the fetal, mammary and uterine components. Feyera and Theil (2017) used a factorial approach to model metabolisable energy (ME) requirement in the last 12 days of gestation, and estimated a $60 \%$ increase in requirement during this time period from 33.9 to 55.6 MJ ME per day (Figure 3). The greatest proportion of required ME (75\% to $80 \%$ ) during the end of gestation is derived from maintenance and depends on sow BW gain (Noblet et al., 1990). Thomas et al. (2018) observed gilt-mobilised fat tissue to meet the energy needed in late gestation for fetal growth and colostrum production. Decaluwe et al. (2014) observed an increase in backfat loss from day 108 to farrowing when sows were only fed $1.5 \mathrm{v} .3 .0 \mathrm{~kg} /$ day of a transition diet. Similarly, Cools et al. (2014) observed that sows fed a lactation diet ad libitum from day 105 of gestation had less backfat thickness loss compared with limit-fed sows. Hansen et al. (2012) observed that total intake of ME from day 108 to 112 of gestation was negatively correlated with piglet weight gain at peak lactation, indicating that a less negative energy balance around parturition is inhibitory for sow milk yield at peak lactation, likely because of the negative impact on feed intake. While energy supply in the peripartum transition period is important to meet changing tissue needs, it is crucial to supply energy without contributing to excess BW gain and backfat stores that will lead to a negative impact in lactation feed intake, milking ability and litter growth.

Colostrum intake is highly correlated with increasing piglet survivability, with a recommended intake of $200 \mathrm{ml}$ per pig in the first $24 \mathrm{~h}$ (Ferrari et al., 2014; Moreira et al., 2017). However, even with the mobilisation of fat reserves before farrowing, sows with low feed intake produced less colostrum and litter weight gain in the first $24 \mathrm{~h}$ (Decaluwe et al., 2014). Sows fed a lactation diet starting on day 104 of gestation produced more colostrum compared with sows fed a gestation diet (Garrison et al., 2017). In contrast, no difference in piglet colostrum intake or sow colostrum yield was observed due to supplemental fat type (Theil et al., 2014) or increased Lys and energy (Gourley at al., 2019).

Colostrum quality, as measured by immunoglobulin $\mathrm{G}$ concentration, has increased when feeding sows a tall oil fatty acid supplement (conjugated linoleic acid source) starting on day 107 of gestation (Hasan et al., 2018) or high Lys and energy from day 113 of gestation to farrowing (Gourley et al., 2019). Colostrum immunoglobulin $\mathrm{G}$ was not increased 
with increased dietary fibre (Loisel et al., 2013). Thus, increased sow energy or amino acid intake in the few days prior to farrowing, during colsotrogenesis, can be beneficial to the colostrum quality.

\section{Fibre use as an energy source in the peripartum transition period}

Several studies have investigated the effects of dietary fibre during the transition period and its influence on colostrum yield, piglet survival and lactation performance. Loisel et al. (2013) fed a low- (13.3\% total dietary fibre) or high(23.4\% total dietary fibre) fibre diet to pigs from day 106 of gestation until parturition. They observed that low-birthweight pigs $(<900 \mathrm{~g})$ from sows fed high-fibre diets had increased colostrum intake, increased colostrum lipid concentrations and a reduction in pre-weaning mortality $(14.7 \%$ v. $6.2 \%)$, but decreased colostrum immunoglobulin A concentrations, and no difference in total sow colostrum yield $(3.9$ v. $3.8 \mathrm{~kg})$. Feyera et al. (2017) fed a dietary fibre-rich supplement ( $22 \%$ crude fibre) to pigs from day 102 of gestation to farrowing $(280 \mathrm{~g} /$ day from day 102 to 108 , and $570 \mathrm{~g} /$ day from day 109 to farrowing) and observed a reduction in stillbirths $(8.8 \% \mathrm{v} .6 .6 \%)$ and decreased piglet death from low viability (2.8\% v. $1.5 \%)$ compared with sows fed a control diet ( $4.1 \%$ crude fibre). The researchers attributed the decrease in stillbirths to a greater amount of shortchain fatty acids available as energy in the colon, or from a reduction in sow constipation. Oliviero et al. (2009) demonstrated that increased fibre feeding pre-farrowing $(7 \% \mathrm{~V}$. $3.8 \%$ crude fibre) reduced constipation around parturition. Guillemet et al. (2010) observed that sows fed a high-fibre diet in gestation (12.8\% v. 3.5\% crude fibre) transitioned more rapidly to a nutrient-dense lactation diet and tended to lose less backfat during the lactation period. However, fibre inclusion during the last 8 to 10 days before farrowing has not been shown to impact birthweight, litter gain, colostrum yield or metabolic criteria of the sow (Loisel et al., 2013; Feyera et al., 2017). Therefore, added fibre during transition may help transition a sow to a lactation diet and reduce stillbirths, but with limited to no impact on colostrum or litter growth.

\section{Amino acids in the peripartum transition period}

Fetal growth $(22.7 \%)$, mammary growth $(16.8 \%)$ and colostrum production (16.1\%) represent the majority of the total required standardised ileal digestible (SID) Lys in late gestation, with the remaining requirement for oxidation/transamination, maintenance and uterine components (Feyera and Theil, 2017). These researchers predicted that relative to day 104 of gestation, the SID Lys requirement increased $149 \%$ by day 115 of gestation to approximately $35 \mathrm{~g}$ of SID Lys per day (Figure 3). This requirement is a significant increase compared with Lys typically provided in commercial production today. Therefore, the sow is likely in a negative Lys balance in the last few days before parturition. Mammary growth increases rapidly in the 10 days prior to farrowing, and will continue to increase up to day 10 of lactation (Kim et al., 1999). The number of pigs determines the amount of Lys and amino acids required, and the sow will mobilise body fat and protein to support litter growth if her feed intake or diet quality is inadequate (Theil, 2015). Recently, it has been demonstrated that birth weight can be increased in gilts by supplying $40 \mathrm{~g}$ SID Lys per day beginning on day 107 or 113 of gestation (Gourley et al., 2019). Additionally, if fetal growth requirements are met, the female will partition increased nutrient intake towards backfat (Garrison et al., 2017; Gourley et al., 2019). It is unknown from these studies whether body protein also increased during this period, but it is well understood that a gilt's requirement for maternal body protein is greater compared with older parity females (Trottier et al., 2014). Thus, gilts may benefit more from an increase in Lys and amino acids in the transition period due to partitioning towards body protein reserves and fetal growth. There is limited data during the transition period to understand the importance of amino acids besides Lys; however, Kim et al. (2009) suggested that in late gestation, the sow requires increased amounts of arginine and leucine for fetal and mammary parenchymal tissues. Therefore, while high dietary Lys can be beneficial during the transition period, more research is needed to understand if additional amino acids will be of benefit for colostrum production and fetal growth.

\section{Lactation}

Although lactation represents only $15 \%$ to $20 \%$ of the productive cycle of a sow, it is undeniably the most metabolically demanding stage of production. The sow's priority in lactation is to sustain milk production for the large and fast-growing litter of piglets, but is often not solely attained by voluntary feed intake. The mobilisation of body fat and protein reserves appears to be critical to support milk production in high-producing sows, although it is unclear whether body mobilisation is an obligatory process in modern sows (Pedersen et al., 2019). The typical negative effects of severe catabolism in lactation on the subsequent reproductive performance of sows is well established (Koketsu et al., 1996), but modern sows seem to be more resilient to the effects of lactational catabolism (Patterson et al., 2011). This distinctive characteristic of the modern sow can be related to changes in biology and body lean composition, although sow resilience over successive parities has not been widely evaluated. Therefore, the main goal of the nutrition program for lactating sows should be to maximise feed intake to sustain milk production, without excessive mobilisation of BW reserves.

\section{Energy requirements in lactation}

The energy requirements of the modern lactating sow have increased significantly along with a marked increase in the number of piglets nursed. Milk production represents $65 \%$ to $80 \%$ of the energy requirements of lactating sows (Figure 4; National Research Council, 2012) and is the reason 
Table 1 Estimated daily milk production and mobilisation of body reserves ${ }^{1}$ of lactating sows according to the number of piglets nursed per sow and weight at weaning

\begin{tabular}{lcccc}
\hline \hline Piglets per litter, $n$ & 10 & 12 & 14 & 16 \\
Piglet weaning weight, kg & 7.0 & 6.8 & 6.4 & 11.8 \\
\hline Milk production, kg/day & 8.7 & 10.3 & 11.3 & -9.3 \\
Sow BW gain, g/day & -206 & -636 & -915 & -968 \\
Sow body protein deposition, g/day & -21 & -63 & -91 & -485 \\
Sow body fat deposition, g/day & -103 & -316 & -482 \\
\hline \hline
\end{tabular}

${ }^{1}$ Estimates derived from the NRC (2012) model assuming a feeding level of $6.5 \mathrm{~kg} /$ day of a lactation diet containing $13.8 \mathrm{MJ}$ metabolisable energy per kilogram in a 21-day lactation for multiparous sows. Piglet growth rate estimated from published studies prior to the genetic selection for piglet birth weight (Beaulieu et al., 2010; Huber et al., 2015; Fan et al., 2016; Strathe et al., 2017a; Pedersen et al., 2019), which is expected to increase piglet weaning weight.

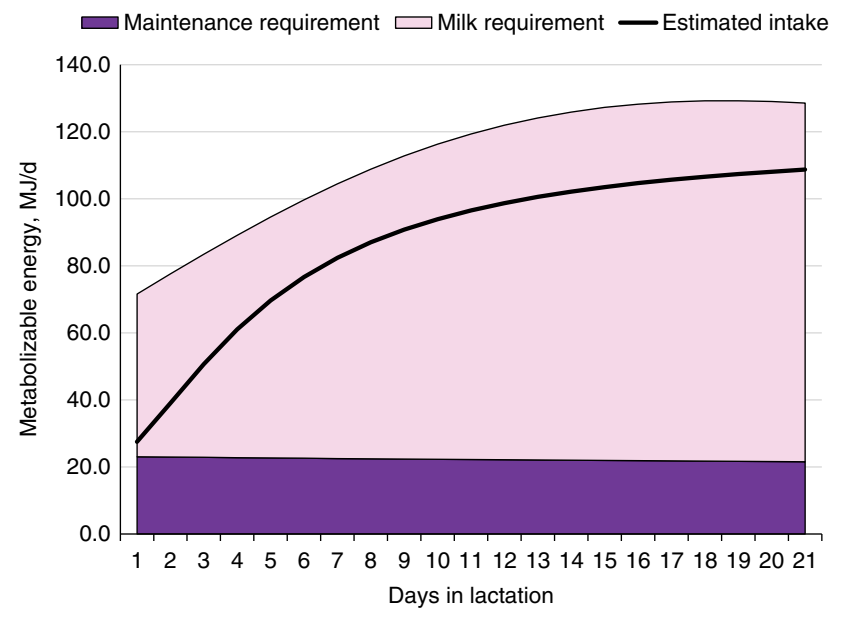

Figure 4 Energy requirement estimates for maintenance and milk production and estimated energy intake of lactating sows. Estimates were derived from the NRC (2012) assuming 14 piglets per litter and $6.4 \mathrm{~kg}$ piglet weaning weight in a 21 -day lactation for multiparous sows.

for an abrupt threefold increase in energy requirement within the first week of farrowing. The energy demand during lactation can impose a metabolic challenge to sows (Pedersen et al., 2019). If energy intake is insufficient, sows prioritise and sustain milk production at the expense of their own body reserves (Table 1). Energy intake is typically lower than lactation requirements, resulting in sows with a negative energy balance during most of lactation (Figure 4; NRC, 2012). This demonstrates the biological inability of lactating sows to consume enough feed to meet the energy requirements and, at the same time, presents an opportunity to develop nutritional strategies to stimulate sows to achieve an optimal level of energy consumption with minimal mobilisation of body reserves.

The energy concentration of lactation diets is an important determinant of energy consumption and is typically modified by the use of fats, oils or fibres in the diet. An increase in dietary energy concentration typically represents an increase in energy intake at the same feed intake until a level at which the dietary energy concentration negatively affects feed intake (Xue et al., 2012). Studies demonstrated that increasing the energy concentration of lactation diets from 12.8 to 13.4 MJ ME/kg improved energy intake and consequently reduced weight loss and increased litter growth rate during lactation (Xue et al., 2012). However, lactation diets with a high energy concentration of 13.8 to $14.2 \mathrm{MJ} \mathrm{ME} / \mathrm{kg}$ had a negative impact on feed intake (Xue et al., 2012) and, thus, did not further increase energy intake.

Increasing energy density with fats or oils is a nutritional strategy that seems to be particularly important for lactating sows under heat stress conditions (Rosero et al., 2012) and for prolific and high-producing lactating sows (Strathe et al., 2017a). In a literature review, the addition of $2 \%$ to $11 \%$ fats and oils in lactation diets improved the energy intake of sows by an average of $7 \%$ or $4.6 \mathrm{MJ}$ ME per day (Rosero et al., 2016). As sows prioritise lactation needs, the additional energy is preferentially partitioned for milk and converted as milk fat output (Rosero et al., 2015). Consequently, the benefits of greater energy intake are observed as improvements in litter growth rate because of a greater amount of energy provided through the milk (Rosero et al., 2015, 2016). Similarly, lactation diets with high levels of dietary fibre resulted in a reduction in energy intake (Schoenherr et al., 1989). Fibrous diets have low energy and bulk density, which physically restrict a sow's ability to consume the volume of feed necessary to achieve a high energy intake (Schoenherr et al., 1989).

In summary, the addition of high-energy ingredients to lactation diets allows an increase in energy intake and energy output in milk. Consequently, there is a reduction in BW loss and an improvement in litter growth rate during lactation.

\section{Amino acid and protein requirements in lactation}

The amino acid requirements of high-producing lactating sows have increased substantially to support the milk production demand of large litters. The number of piglets nursed per sow as well as the litter growth rate during lactation dictate the amino acid requirements of lactating sows (Table 2). The amino acids for milk production represent most of the requirements, as lactating sows utilise as much as $70 \%$ of dietary protein for milk protein synthesis (Pedersen et al., 2016). It appears that milk production is hardly changed by lactation diet because sows are able to mobilise body reserves (Noblet and Etienne, 1987). However, the supply of dietary amino acids and CP close to the requirements can improve milk protein output (Strathe et al., 2017b) 
Tokach, Menegat, Gourley and Goodband

Table 2 Daily lysine requirement estimates ${ }^{1}$ (grams of standardised ileal digestible lysine per day) of lactating sows according to the number of piglets nursed per sow and weight at weaning

\begin{tabular}{lllll}
\hline \hline & \multicolumn{3}{c}{ Piglets per litter, $n$} \\
\cline { 2 - 5 } Piglet weaning weight, $\mathrm{kg}$ & 10 & 12 & 14 & 16 \\
\hline 5.8 & 43.0 & 47.5 & 52.2 & 57.0 \\
6.0 & 43.8 & 48.3 & 53.2 & 58.4 \\
6.4 & 45.3 & 50.2 & 57.5 & 60.7 \\
6.8 & 46.8 & 52.0 & 58.6 & 63.2 \\
7.0 & 47.5 & 53.0 & 64.3 \\
\hline \hline
\end{tabular}

${ }^{1}$ Estimates derived from the NRC (2012) model assuming a feeding level of $6.5 \mathrm{~kg} /$ day of a lactation diet containing $13.8 \mathrm{MJ}$ metabolisable energy per kilogram in a 21 day lactation for multiparous sows. For primiparous sows, the lysine requirements in grams per day are approximately $5 \%$ lower due to lower milk production but approximately $5 \%$ higher as a diet percentage due to lower feed intake. Piglet growth rate estimated from published studies prior to the genetic selection for piglet birth weight (Beaulieu et al., 2010; Huber et al., 2015; Fan et al., 2016; Strathe et al., 2017a; Pedersen et al., 2019), which is expected to increase piglet weaning weight.

and reduce muscle protein mobilisation in lactating sows (Gourley et al., 2017; Pedersen et al., 2019). Recent studies underline that a dietary intake of both balanced protein and essential amino acids is mutually important to sow and litter performance during lactation (Strathe et al., 2017b; Huber et al., 2018; Pedersen et al., 2019).

Dietary intake of balanced protein supplies essential amino acids and nitrogen necessary to synthesise non-essential amino acids. The high-producing sow seems to benefit from a balanced protein intake during lactation by improving litter growth rate and reducing BW loss (Strathe et al., 2017b, Pedersen et al., 2019). Studies with high feed-grade amino acids suggested that increasing digestible CP up to 13.5\% (approximately $15.5 \%$ CP) improved litter growth rate by increasing sow milk protein output (Strathe et al., 2017b). Higher levels of digestible CP of $14.3 \%$ (approximately $16.5 \%$ CP) seemed to minimise sow BW loss by sparing muscle protein mobilisation for the purpose of milk production (Strathe et al., 2017b). Thus, lactation diets may need a minimum digestible CP content of $13.5 \%$ to $14.3 \%$.

Recently, several studies have evaluated amino acid requirements to ensure optimum performance of high-producing lactating sows. In general, the amino acid requirement estimates vary depending on performance criteria and statistical methodology applied in the study. Lysine requirement estimates are the most frequently studied, as models predict a substantial increase in Lys requirements of lactating sows with large, fast-growing litters (Table 2). The literature seems to agree on the effect of increasing dietary Lys intake to reduce BW loss and body protein mobilisation, but is conflicting in terms of the influence of dietary Lys intake on litter growth rate and subsequent reproductive performance (Xue et al., 2012; Shi et al., 2015; Gourley et al., 2017). Studies using a range of 0.50 to $0.81 \mathrm{~g}$ SID Lys per MJ ME determined that the Lys requirement estimate to minimise sow BW loss in the lactation period is around 0.72 to $0.79 \mathrm{~g}$ SID Lys per MJ ME (Xue et al., 2012; Shi et al., 2015; Gourley et al., 2017). Although the estimates seemed to be within the same range for primiparous and multiparous sows, the BW loss has been reported to be considerably greater in primiparous than multiparous sows, at around
12\% (Shi et al., 2015) and 7\% (Xue et al., 2012; Gourley et al., 2017), respectively. The reduction in sow BW loss is presumably the consequence of a low mobilisation of muscle protein, as evidenced by a reduction in loin eye depth loss during lactation (Shi et al., 2015; Gourley et al., 2017). Lower concentrations of plasma urea nitrogen and plasma creatinine as a result of increased Lys intake support a reduction in sow body protein utilisation and muscle catabolism (Xue et al., 2012). However, there is no consensus on the effect of dietary Lys on body fat stores (Shi et al., 2015; Gourley et al., 2017). It is proposed that the mobilisation of energy and protein are not completely independent. Thus, the interaction between amino acid and energy requirements is more complex and subject to factors involved in nutrient deficit, including energy and protein intake, energy and protein output in milk, growth rate of the litter and lactation length (Dourmad et al., 2008).

Milk production and milk composition are arguably the most important factors capable of stimulating and supporting an improvement in litter growth rate (Strathe et al., 2017b). However, the influence of dietary Lys intake on milk production and composition is not well understood. In a study with primiparous sows, milk protein content increased with dietary Lys levels up to $0.81 \mathrm{~g}$ SID Lys per MJ ME in a range of 0.55 to $0.81 \mathrm{~g}$ SID Lys per MJ ME (Shi et al., 2015), but no other recent Lys requirement studies have evaluated sow milk composition (Xue et al., 2012; Gourley et al., 2017). In contrast, an increase in milk protein content is not reflected in an improved growth rate of primiparous litters (Shi et al., 2015). While some studies observed no influence of dietary Lys intake on the growth rate of primiparous litters (Shi et al., 2015; Gourley et al., 2017), others suggested an improvement in litter growth rate up to 0.72 to $0.79 \mathrm{~g}$ SID Lys per MJ ME for primiparous and multiparous sows (Xue et al., 2012; Gourley et al., 2017). Estimating Lys requirements for litter growth rate is seemingly complex due to the capacity of sows to maintain milk production and sustain litter growth rate by mobilising body reserves (Noblet and Etienne, 1987). Moreover, the estimation of Lys requirements for litter growth rate probably requires a multifactorial approach by taking into account parity, lactation curve, daily Lys intake, 


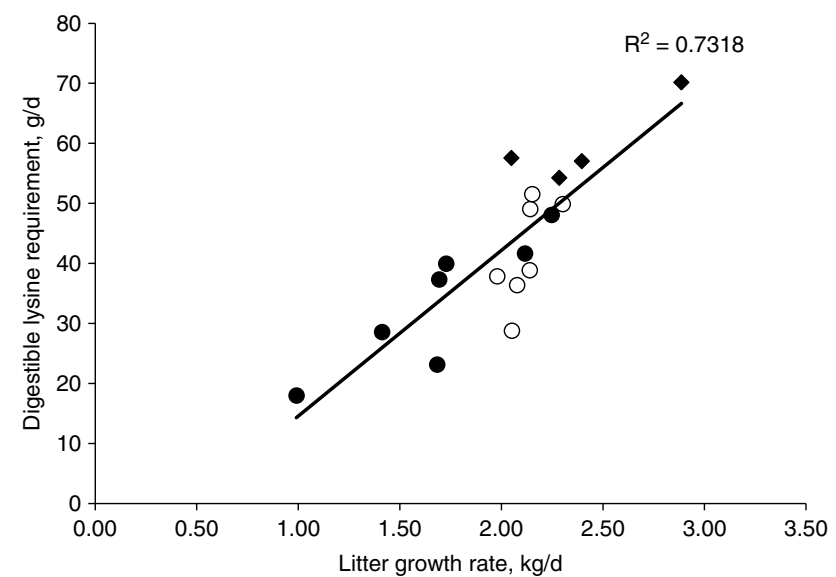

Figure 5 Regression curve to estimate the digestible lysine requirement to optimise litter growth rate from published studies. The regression curve originally derived from published lysine requirement studies from 1972 to 1997 summarised by Pettigrew (1993) in the solid circles and Boyd et al. (2000) in the open circles. The present updated curve contains data from studies published from 1998 to 2017, represented by the diamonds. The updated regression indicates that $27 \mathrm{~g}$ of digestible lysine intake per day is needed for each $1 \mathrm{~kg}$ of litter growth, and sows are expected to mobilise $13 \mathrm{~g}$ of lysine per day from body protein reserves.

growth rate of the litter, milk production and milk composition, as these factors affect how Lys is required and partitioned by lactating sows.

Interestingly, the amount of daily digestible Lys intake per kilogram of litter daily gain is consistent around 24 to $25 \mathrm{~g}$ for the recent studies on Lys requirements to improve litter growth rate for lactating sows (Xue et al., 2012; Gourley et al., 2017). Previous reviews conducted by Pettigrew (1993) and Boyd et al. (2000) determined a positive correlation between increased Lys requirements and litter growth rate. The regression using published data from 1972 to 1997 indicated that $26 \mathrm{~g}$ of total Lys or approximately $22 \mathrm{~g}$ of digestible lysine intake per day is needed for each $1 \mathrm{~kg}$ of litter growth, and sows are expected to mobilise $8 \mathrm{~g}$ of Lys per day from body protein reserves (Boyd et al., 2000). The original equation has been updated (Figure 5) with Lys requirements for optimal litter growth rate from published studies conducted between 1998 and 2017 with primiparous and multiparous sows (Sauber et al., 1998; Yang et al., 2000, Xue et al., 2012; Gourley et al., 2017). The new regression predicted an increase to $27 \mathrm{~g}$ per day in the amount of digestible Lys intake required for each $1 \mathrm{~kg}$ of litter growth, and also an increase to $13 \mathrm{~g}$ per day in the expected mobilisation of Lys from body protein reserves. This predicted increase in the estimates of both Lys requirement and mobilisation of reserves coincides with the expectation for modern sows, which are leaner and higher milk producers than sow genotypes in the past.

It is well recognised that excessive weight loss and mobilisation of body reserves during lactation are associated with a prolonged wean-to-oestrus interval and inferior subsequent reproductive performance in sows (King, 1987; Koketsu et al., 1996). Thus, the attenuation of lactational catabolism with an increase in dietary Lys intake in lactating sows (Xue et al., 2012; Shi et al., 2015; Gourley et al., 2017) has been intuitively related to improvements in subsequent reproduction. Early studies consistently demonstrated the effect of amino acid intake on improving wean-to-oestrus interval and litter size (King, 1987; Touchette et al., 1998), mediated by the release of reproductive and metabolic hormones (King and Martin, 1989; Tokach and Dial, 1992). However, the influence of dietary Lys intake on subsequent reproductive performance of modern sows is not as clear based on recent studies. There is evidence to suggest an improvement in the secretion of estradiol and luteinising hormone in primiparous and multiparous sows around the peak of lactation with dietary Lys levels of 0.72 to $0.79 \mathrm{~g}$ SID Lys per MJ ME (Xue et al., 2012). These hormones play an important role in follicular development during lactation and cyclicity return after weaning (Soede et al., 2011). Indeed, the same study demonstrated a short wean-to-oestrus interval with dietary Lys levels of 0.72 to $0.79 \mathrm{~g}$ SID Lys per MJ ME (Xue et al., 2012). However, there is no consensus in the literature (Shi et al., 2015; Gourley et al., 2017). For primiparous sows, Gourley et al. (2017) fed dietary SID Lys of 0.52 to $0.81 \mathrm{~g}$ per MJ ME and observed an improvement in the number bred within 7 days after weaning; however, the effect on wean-to-oestrus interval is not consistent (Xue et al., 2012; Shi et al., 2015; Gourley et al., 2017). The effect of dietary Lys on reproductive hormones during the first lactation was not evident in another recent study (Shi et al., 2015). Likewise, dietary Lys levels during lactation did not seem to have an influence on the conception rate (Shi et al., 2015) or the number of piglets born in the subsequent parturition (Gourley et al., 2017).

The lack of a clear influence of dietary Lys intake during lactation on reproduction in the subsequent cycle seemed to corroborate with the remark that the reproductive performance of modern primiparous sows is increasingly resilient to the negative effects of tissue catabolism during lactation (Patterson et al., 2011). Greater protein reserves of modern sows may provide more reserves to limit the dietary amino acid influence on subsequent reproduction.

The requirements of essential amino acids in milk and mammary gland tissue increase as the number of piglets nursed increases (Kim et al., 2001). The most limiting amino acids for milk production are typically Lys, threonine and valine (Kim et al., 2001; Soltwedel et al., 2006); thus, the requirements of the latter amino acids as a ratio to Lys have been recently re-evaluated for high-producing lactating sows. The threonine requirement estimate to optimise the litter growth rate of lactating sows was approximately $65 \%$ of SID Lys with a range of $52 \%$ to $84 \%$ (Greiner et al., 2018). However, the lack of other threonine requirement studies with modern lactating sows hinders the validation of threonine requirement estimates.

Recent studies did not reach a consensus about the requirement estimates of valine as a ratio to Lys. Valine concentrations above $76 \%$ of SID Lys provide no improvement in litter growth rate and sow backfat loss in a valine range of $76 \%$ to $97 \%$ of SID Lys (Strathe et al., 2016). However, an 
Tokach, Menegat, Gourley and Goodband

Table 3 Daily phosphorus requirement estimates ${ }^{1}$ (grams of standardised total tract digestible phosphorus per day) of lactating sows according to the number of piglets nursed per sow and weight at weaning

\begin{tabular}{lllll}
\hline \hline & \multicolumn{3}{c}{ Piglets per litter, $n$} \\
\cline { 2 - 5 } Piglet weaning weight, $\mathrm{kg}$ & 10 & 12 & 14 & 16 \\
\hline 5.8 & 17.5 & 20.3 & 23.3 & 26.3 \\
6.0 & 18.1 & 20.9 & 24.0 & 27.2 \\
6.4 & 19.2 & 22.2 & 25.5 & 28.9 \\
6.8 & 20.2 & 23.5 & 27.0 & 30.7 \\
7.0 & 20.7 & 24.2 & 27.8 & 31.5 \\
\hline \hline
\end{tabular}

${ }^{1}$ Estimates derived from the NRC (2012) model assuming a feeding level of $6.5 \mathrm{~kg} /$ day of a lactation diet containing $13.8 \mathrm{MJ}$ metabolisable energy per kilogram in a 21-day lactation for multiparous sows. For primiparous sows, phosphorus requirements in grams per day are approximately $5 \%$ lower due to lower milk production but approximately $5 \%$ higher as a diet percentage due to lower feed intake. Total calcium intake is estimated at two times the digestible phosphorus requirement. Piglet growth rate estimated from published studies prior to the genetic selection for piglet birth weight (Beaulieu et al.,2010; Huber et al., 2015; Fan et al., 2016; Strathe et al., 2017a; Pedersen et al., 2019), which is expected to increase piglet weaning weight.

improvement in both criteria was evident with very high levels of valine (113\% of SID Lys) for litter growth rate and $88 \%$ of SID Lys for minimising backfat loss (Xu et al., 2017). The requirement for valine in lactating sow diets seemed to be independent of total branched-chain amino acid concentrations, indicating that leucine and isoleucine do not spare the requirement of valine for sows in lactation (Moser et al., 2000).

The requirement for tryptophan for lactating sows has been estimated to be $22 \%$ of SID Lys to maximise feed intake and at $26 \%$ of SID Lys to minimise BW loss in primiparous sows, with no effect on multiparous sows (Fan et al., 2016). However, similar to threonine, the lack of other tryptophan requirement studies with modern lactating sows hinders the validation of tryptophan requirement estimates. Furthermore, studies evaluating the requirements of branched-chain amino acids and sulphur-containing amino acids, among others, for high-producing lactating sows are non-existent in recent literature.

The variation in amino acid requirements for lactating sows could be a consequence of the dynamic body tissue mobilisation during lactation (Kim et al., 2009). The ideal dietary amino acid profile for lactating sows is influenced by the amino acid profile in milk and mammary gland tissue, and the amino acid resulting from body tissue mobilisation (Kim et al., 2001). Because of these differences, threonine is a critical amino acid for sows with low lactation feed intake and substantial mobilisation of body reserves during lactation, whereas valine is an important amino acid for sows with high feed intake and limited mobilisation of body reserves during lactation (Kim et al., 2001; Soltwedel et al., 2006). Although the second- and third-limiting amino acids for lactating sows vary according to body tissue mobilisation, Lys is consistently the first-limiting amino acid (Kim et al., 2001; Soltwedel et al., 2006).

In summary, the dietary provision of amino acids close to the requirements of lactating sows allows a reduction in body protein mobilisation and has the potential to improve litter growth rate. The influence of amino acid intake on sow and litter performance seems to be even more complex for primiparous sows, as recent studies failed to report an amino acid-derived improvement in performance during the first lactation.

\section{Calcium and phosphorus requirements in lactation}

Calcium and phosphorus requirements for high-producing lactating sows have been currently estimated using a modelling approach (NRC, 2012). A scarcity of recent research prevents the validation of model-derived requirement estimates. The dynamic mobilisation of calcium and phosphorus in catabolic sows during lactation adds complexity to their requirement estimates using empirical studies.

The requirement estimates of calcium and phosphorus for lactating sows are primarily influenced by milk production (NRC, 2012). High-producing lactating sows with large, fast-growing litters have a considerable increase in calcium and phosphorus requirements (Table 3 ) in order to support their demand in milk production (Table 4). Moreover, calcium and phosphorus requirements are expected to increase throughout the lactation period following the sow milk production curve. The dietary intake of calcium and phosphorus is of great importance for primiparous sows to support their growth and development of bone and muscle tissues (NRC, 2012). Moreover, calcium and phosphorus are likely more critical for primiparous sows that might not have these mineral reserves for mobilisation as a multiparous sow.

\section{Practical considerations in feeding programs}

Diet formulation is only one step in developing a feeding program for today's sow. High feed intake is necessary to meet the energy and amino acid requirements of high-producing sows. The feeding system, environment, sow body condition and choice of ingredients will influence daily feed intake during lactation and have as much impact on sow productivity as nutrient levels in the diet.

\section{Advances in feed delivery systems}

Producers and researchers have long debated whether feed should be gradually increased during the first week of 
Table 4 Estimated daily calcium and phosphorus output ${ }^{1}$ in sow milk according to the number of piglets nursed per sow and weight at weaning

\begin{tabular}{lllll}
\hline \hline Piglets per litter, $n$ & 10 & 12 & 14 & 16 \\
Piglet weaning weight, kg & 7.0 & 6.8 & 6.4 & 5.8 \\
\hline Total calcium milk output, g/day & 27.4 & 32.3 & 35.7 & 36.9 \\
STTD phosphorus milk output, g/day & 13.7 & 16.2 & 17.9 & 18.5 \\
\hline \hline
\end{tabular}

STTD $=$ standardised total tract digestible.

${ }^{1}$ Estimates derived from the NRC (2012). Milk phosphorus is predicted from milk nitrogen output at a ratio between standardised total tract digestible phosphorus and nitrogen of 0.196 . Milk calcium is predicted from milk phosphorus output at a ratio between total calcium and standardised total tract digestible phosphorus of 2 . Piglet growth rate estimated from published studies prior to the genetic selection for piglet birth weight (Beaulieu et al., 2010; Huber et al., 2015; Fan et al., 2016; Strathe et al., 2017a; Pedersen et al., 2019), which is expected to increase piglet weaning weight.

lactation or provided ad libitum immediately after farrowing. Research in this area is not new, but continually showed that ad libitum feeding mostly results in a higher feed intake over the entire lactation phase than step-up programs (Stahly et al., 1979; Moser et al., 1987). The increased size of swine facilities coupled with advances in equipment design have made ad libitum feed delivery a reality in most large production systems.

\section{Environment and sow intake}

Sows maintained in the thermoneutral zone will have a higher feed intake than sows experiencing heat stress. McGlone et al. (1988) demonstrated that drip coolers were more effective at relieving heat stress than snout coolers or increases in diet energy density. Black et al. (1993) summarised that 'increasing heat loss from the sow, particularly through increasing the area of wet skin, has a greater positive effect on animal performance than modifying the diet'. An increased use of evaporative cool cells and drip coolers allows farms in hot climates to greatly increase feed intake compared to not using these technologies.

\section{Gestation body condition}

Numerous studies have demonstrated that sows with a higher backfat at farrowing have a lower feed intake during lactation than sows with a lower backfat at farrowing. Dourmad (1993) found that providing high levels of feed intake during gestation decreased lactation feed intake by resulting in smaller meals and shorter feeding duration. Increasing the fibre in gestation diet, while providing the same energy intake, increased meal frequency during lactation, but did not increase feed intake (Guillemet et al., 2006). Data from more modern sows (Kim et al., 2015) illustrate that lactation feed intake decreases linearly as backfat before farrowing increases, with the greatest decrease in feed intake for sows with $>20 \mathrm{~mm}$ of backfat at farrowing.

Producers understand the importance of maintaining sows in the correct body condition, but have difficulty achieving the goal in the field. Sows are often over- or underconditioned on individual farms. Although ultrasound is a better tool to assess sow backfat than body condition score (Young et al., 2004), it can be too time-consuming and difficult to accomplish in the field. The invention of a sow caliper
(Knauer and Baitinger, 2015) provides a fast, unbiased tool for producers to assess body condition.

\section{Phase feeding}

The information provided in this review suggests that phase feeding may provide benefits for lactating sows. A peripartum diet fed prior to and immediately after farrowing may be targeted towards reducing stillbirths and encouraging sow feed consumption. A lactation diet, fed for the remainder of lactation, would be designed for optimal milk production and subsequent reproduction. The use of a lower nutrient-dense diet until day 10 after farrowing lowered feed cost, but did not influence the performance of sows in a Danish commercial study (Sorensen, 2007). Similarly, Craig et al. (2016) found that feeding a constant energy level during lactation resulted in similar performance to sows that were offered a lower energy diet before day 14 and a higher energy diet after day 14 of lactation. Conversely, Pedersen et al. (2016) found that altering the diet to meet the sows' changing requirements as lactation progressed increased sow milk yield and pig weaning weight compared with feeding a single lactation diet; however, the single lactation diet used in the study was below the sow's requirement for amino acids for much of lactation. Thus, more research is needed to determine if providing two different diets during lactation provides any productivity benefits compared with feeding a single lactation diet that more closely meets the sows' requirements.

\section{Conclusion}

In summary, the lactating sow has demonstrated remarkable resiliency in the face of rapid improvements in production and nutritional challenges. Many practical aspects of meeting the nutrient requirements of high-producing sows have not changed. With increased milk production, amino acid and energy requirements must be met in order to avoid excessive body tissue catabolism. Future research needs to continue to improve our understanding of sow's requirements during the peripartum transition period to reduce farrowing duration and increase pig survival. Our knowledge of these and other facets of sow management will ultimately improve the welfare of the sow and her offspring. 


\section{Acknowledgements}

The authors thank Dr. Matt Culbertson at Genus PIC for providing genetic trend data, and Elsevier for allowing the use of copyrighted material.

(D) Michael D Tokach, 0000-0002-9621-362X

\section{Declaration of interest}

There are no conflicts of interest to declare.

\section{Ethics committee}

All work is within guidelines and requirements of ethics committees.

\section{Software and data repository resources}

None of the data were deposited in an official repository.

\section{References}

Agriculture and Horticulture Development Board (AHDB) 2017. 2016 Pig cost of production in selected countries. Retrieved on 5 March 2019, from https://pork. ahdb.org.uk/media/274535/2016-pig-cost-of-production-in-selected-countries. pdf

Beaulieu AD, Aalhus JL, Williams NH and Patience JF 2010. Impact of piglet birth weight, birth order, and litter size on subsequent growth performance, carcass quality, muscle composition, and eating quality of pork. Journal of Animal Science 88, 2767-2778.

Black JL, Mullan BP, Lorschy ML and Giles LR 1993. Lactation in the sow during heat stress. Livestock Production Science 35, 153-170.

Boyd RD, Touchette KJ, Castro GC, Johnston ME, Lee KU and Han IK 2000. Recent advances in amino acid and energy nutrition of prolific sows - review. Asian-Australasian Journal of Animal Sciences 13, 1638-1652.

Cools A, Maes D, Decaluwe R, Buyse J, van Kempen TATG, Liesegang A and Janssens GPJ 2014. Ad libitum feeding during the peripartal period affects body condition, reproduction results and metabolism of sows. Animal Reproduction Science 145, 130-140.

Craig A, Henry W, and Magowan E 2016. Effect of phase feeding and valine-tolysine ratio during lactation on sow and piglet performance. Journal of Animal Science 94, 3835-3843.

Decaluwe R, Maes D, Cools A, Wuyts B, De Smet S, Marescau B, De Deyn PP and Janssens GPJ 2014. Effect of peripartal feeding strategy on colostrum yield and composition in sows. Journal of Animal Science 92, 3557-3567.

Devillers N, Farmer C, Mounier AM, Le Dividich J and Prunier A 2004. Hormones, IgG and lactose changes around parturition in plasma, and colostrum or saliva of multiparous sows. Reproduction Nutrition Development 44, 381-396.

Dourmad JY 1993. Standing and feeding behaviour of the lactating sow: effect of feeding level during pregnancy. Applied Animal Behaviour Science 37, 311-319. Dourmad J-Y, Étienne M, Valancogne A, Dubois S, van Milgen J and Noblet J 2008. InraPorc: A model and decision support tool for the nutrition of sows. Animal Feed Science and Technology 143, 372-386.

Fan ZY, Yang XJ, Kim J, Menon D and Baidoo SK 2016. Effects of dietary tryptophan : lysine ratio on the reproductive performance of primiparous and multiparous lactating sows. Animal Reproduction Science 170, 128-134.

Ferrari CV, Sbardella PE, Bernardi ML, Coutinho ML, Vaz Jr. IS Wentz I and Bortolozzo FP 2014. Effect of birth weight and colostrum intake on mortality and performance of piglets after cross-fostering in sows of different parities. Journal of Preventative Veterinary Medicine 114, 259-266.

Feyera T and Theil PK 2017. Energy and lysine requirements and balances of sows during transition and lactation: A factorial approach. Livestock Science 201(Supplement C), 50-57.

Feyera T, Hojgaard CK, Vinther J, Bruun TS and Theil PK 2017. Dietary supplement rich in fiber fed to late gestating sows during transition reduces rate of stillborn piglets. Journal of Animal Science 95, 5430-5438.
Feyera T, Pedersen TF, Krogh U, Foldager L and Theil PK 2018. Impact of sow energy status during farrowing on farrowing kinetics, frequency of stillborn piglets, and farrowing assistance. Journal of Animal Science 96, 2320-2331.

Garrison C, van Heugten E, Wiegert JG and Knauer MT 2017. Got colostrum? Effect of diet and feeding level on piglet colostrum intake and piglet quality. Journal of Animal Science 95 (suppl. 2), 113.

Gourley KM, Nichols GE, Sonderman JA, Spencer ZT, Woodworth JC, DeRouchey JM, Dritz SS, Goodband RD, Kitt SJ and Stephenson EW 2017. Determining the impact of increasing standardized ileal digestible lysine for primiparous and multiparous sows during lactation. Translational Animal Science 1, 426-436.

Gourley KM, Swanson AJ, Woodworth JC, DeRouchey JM, Tokach MT, Dritz SS, Goodband RD and Frederick B 2019. Effects of increasing duration of feeding high dietary lysine and energy prior to farrowing on sow and litter performance under commercial conditions. Journal of Animal Science (In press)

Greiner L, Srichana P, Usry JL, Neill C, Allee GL, Connor J, Touchette KJ and Knight CD 2018. The use of feed-grade amino acids in lactating sow diets. Journal of Animal Science and Biotechnology 9, 3.

Guillemet R, Dourmad JY and Meunier-Salaun MC 2006. Feeding Behavior in primiparous lactating sows: Impact of a high-fiber diet during pregnancy. Journal of Animal Science 84, 2474-2481.

Guillemet R, Guerin C, Richard F, Dourmad JY and Meunier-Salaun MC 2010. Feed transition between gestation and lactation is exhibited earlier in sows fed a high-fiber diet during gestation. Journal of Animal Science 88, 2637-2647. Hansen AV, Lauridsen C, Sørensen MT, Bach Knudsen KE and Theil PK 2012. Effects of nutrient supply, plasma metabolites, and nutritional status of sows during transition on performance in the next lactation. Journal of Animal Science 90, 466-480.

Hasan S, Saha S, Junnikkala S, Orro T, Peltoniemi 0 and Oliviero C 2018. Late gestation diet supplementation of resin acid-enriched composition increases sow colostrum immunoglobulin $\mathrm{G}$ content, piglet colostrum intake and improve sow gut microbiota. Animal. doi: 10.1017/S1751731118003518. Published online by Cambridge University Press 27 December 2018.

Huber L-A, Rudar M, Trottier NL, Cant JP and de Lange CFM 2018. Whole-body nitrogen utilization and tissue protein and casein synthesis in lactating primiparous sows fed low- and high-protein diets. Journal of Animal Science 96, 2380-2391.

Huber L, de Lange CFM, Krogh U, Chamberlin D and Trottier NL 2015. Impact of feeding reduced crude protein diets to lactating sows on nitrogen utilization. Journal of Animal Science 93, 5254-5264.

Kim SW, Baker DH and Easter RA 2001. Dynamic ideal protein and limiting amino acids for lactating sows: The impact of amino acid mobilization. Journal of Animal Science 79, 2356-2366.

Kim JS, Yang X, Pangeni D and Baidoo SK 2015. Relationship between backfat thickness of sows during late gestation and reproductive efficiency at different parities. Acta Agriculturae Scandinavica 65, 1-8.

Kim SW, Hurley WL, Han IK and Easter RA 1999. Effect on nutrient intake on mammary gland growth in lactating sows. Journal of Animal Science 77 , 3304-3315.

Kim SW, Hurley WL, Wu G and Ji F 2009. Ideal amino acid balance for sows during gestation and lactation. Journal of Animal Science 87(E. Suppl.), E123-E132.

King RH 1987. Nutritional anoestrus in young sows. Pig News Info 8, 15-22.

King RH and Martin GB 1989. Relationships between protein intake during lactation, LH levels and oestrous activity in first-litter sows. Animal Reproduction Science 19, 283-292.

Knauer MT and Baitinger DJ 2015. The sow body condition caliper. Applied Science and Engineering Community of ASABE 31, 175-178.

Koketsu Y, Dial GD, Pettigrew JE, Marsh WE and King VL 1996. Characterization of feed intake patterns during lactation in commercial swine herds. Journal of Animal Science 74, 1202-1210.

Loisel F, Farmer C, Ramaekers P and Quesnel H 2013. Effects of high fiber intake during late pregnancy on sow physiology, colostrum production, and piglet performance. Journal of Animal Science 91, 5269-5279.

McGlone JJ, Stansbury WF and Tribble LF 1988. Management of lactating sows during heat stress: Effects of water trip, snout coolers, floor type and a high energy-density diet. Journal of Animal Science 66, 885-891.

Manu H, Pangeni D, Wilcock P and Baidoo SK 2018. The effect of superdosing phytase from 109 days of gestation through lactation on farrowing duration, piglet and sow performance. Journal of Animal Science 96(E. Suppl.), 148. 
Martineau GP, Le Treut Y, Guillou D, Waret-Szkuta A 2013. Postpartum dysgalactia syndrome: A simple change in homeorhesis? Journal of Swine Health and Production 21, 85-93.

Moreira LP, Menegat MB, Barros GP, Bernardi ML, Wentz I and Bortolozzo FP 2017. Effects of colostrum, and protein and energy supplementation on survival and performance of low-birth-weight piglets. Livestock Science 202, 188-193.

Moser RL, Cornelius SG, Pettigrew JE, Hanke HE, Heeg TR and Miller KP 1987. Influence of postpartum feeding method on performance of the lactating sow. Livestock Production Science 16, 91-99.

Moser SA, Tokach MD, Dritz SS, Goodband RD, Nelssen JL and Loughmiller JA 2000. The effects of branched-chain amino acids on sow and litter performance. Journal of Animal Science 78, 658-667.

National Research Council (NRC) 2012. Nutrient requirements of swine, 11th revised edition. National Academy Press, Washington, DC, USA.

Noblet J and Etienne M 1987. Metabolic utilization of energy and maintenance requirements in lactating sows. Journal of Animal Science 64, 774-781.

Noblet J, Dourmad JY and Etienne M 1990. Energy utilization in pregnant and lactating sows: Modeling of energy requirements. Journal of Animal Science 68 , 562-572.

Oliviero C, Kokkonen T, Heinonen M, Sankari S and Peltoniemi OAT 2009. Feeding sows with high fiber diet around farrowing and early lactation: Impact on intestinal activity, energy balance related parameters and litter performance. Research in Veterinary Science 86, 314-319.

Oliviero C, Heinonen M, Valros A and Peltoniemi OAT 2010. Environment and sow-related factors affecting the duration of farrowing. Animal Reproduction Science 119, 85-91.

Patterson JL, Smit MN, Novak S, Wellen AP and Foxcroft GR 2011. Restricted feed intake in lactating primiparous sows. I. Effects on sow metabolic state and subsequent reproductive performance. Reproduction, Fertility and Development 23, 889-898.

Pedersen TF, Bruun TS, Feyera T, Larsen UK and Theil PK 2016. A two-diet feeding regime for lactating sows reduced nutrient deficiency in early lactation and improved milk yield. Livestock Science 191, 165-173.

Pedersen TF, Chang CY, Trottier NL, Bruun TS and Theil PK 2019. Effect of dietary protein intake on energy utilization and feed efficiency of lactating sows. Journa of Animal Science 97, 779-793.

Pettigrew JE 1993. Amino acid nutrition of gestating and lactating sows. Biokyowa Technical Reviews 5, St. Louis, MO, USA.

Rosero DS, Boyd RD, Odle J and van Heugten E 2016. Optimizing dietary lipid use to improve essential fatty acid status and reproductive performance of the modern lactating sow: A review. Journal of Animal Science and Biotechnology 7, 34

Rosero DS, Odle J, Mendoza SM, Boyd RD, Fellner V and van Heugten E 2015 Impact of dietary lipids on sow milk composition and balance of essential fatty acids during lactation in prolific sows. Journal of Animal Science 93 2935-2947.

Rosero DS, van Heugten E, Odle J, Arellano C and Boyd RD 2012. Response of the modern lactating sow and progeny to source and level of supplemental dietary fat during high ambient temperatures. Journal of Animal Science 90, 26092619.

Sauber TE, Stahly TS, Williams NH and Ewan RC 1998. Effect of lean growth genotype and dietary amino acid regimen on the lactational performance of sows. Journal of Animal Science 76, 1098-1111.

Schoenherr WD, Stahly TS and Cromwell GL 1989. The effects of dietary fat or fiber addition on yield and composition of milk from sows housed in a warm or hot environment. Journal of Animal Science 67, 482-495.

Shi M, Zang J, Li Z, Shi C, Liu L, Zhu Z and Li D 2015. Estimation of the optimal standardized ileal digestible lysine requirement for primiparous lactating sows fed diets supplemented with crystalline amino acids. Animal Science Journal 86, 891-896.

Soede NM, Langendijk P and Kemp B 2011. Reproductive cycles in pigs. Animal Reproduction Science 124, 251-258.
Soltwedel KT, Easter RA and Pettigrew JE 2006. Evaluation of the order of limitation of lysine, threonine, and valine, as determined by plasma urea nitrogen, in corn-soybean meal diets of lactating sows with high body weight loss. Journal of Animal Science 84, 1734-1741.

Sorensen G 2007. Phase feeding of lactating sows. Retrieved on 26 February 2019, http://www.pigresearchcentre.dk/Research/Sow\%20and\%20piglets/785. aspx

Stahly TS, Cromwell GL and Simpson WS 1979. Effects of full vs restricted feeding of sows immediately postpartum on lactation performance. Journal of Animal Science 49, 50-54.

Strathe AV, Bruun TS, Zerrahn J-E, Tauson A-H and Hansen CF 2016. The effect of increasing the dietary valine-to-lysine ratio on sow metabolism, milk production, and litter growth. Journal of Animal Science 94, 155-164.

Strathe AV, Bruun TS and Hansen CF 2017a. Sows with high milk production had both a high feed intake and high body mobilization. Animal 11, 1913-1921.

Strathe AV, Bruun TS, Geertsen N, Zerrahn J-E and Hansen CF 2017b. Increased dietary protein levels during lactation improved sow and litter performance. Animal Feed Science and Technology 232, 169-181.

Theil PK, Flummer C, Hurley WL, Kristensen NB, Labouriau RL and Sorensen MT 2014. Mechanistic model to predict colostrum intake based on deuterium oxide dilution technique data and impact of gestation and prefarrowing diets on piglet intake and sow yield of colostrum. Journal of Animal Science 92. 5507-5519.

Theil PK 2015. Transition feeding of sows. In The gestating and lactating sow (ed. C Farmer), pp. 147-167. Wageningen Academic Publishers, Wageningen, The Netherlands.

Thomas LL, Goodband RD, Tokach MD, Woodworth JC, DeRouchey JM and Dritz SS 2018. Effect of parity and stage of gestation on growth and feed efficiency of gestating sow. Journal of Animal Science 96, 4327-4338.

Tokach MD and Dial GD 1992. Managing the lactating sow for optimal weaning and rebreeding performance. Veterinary Clinics of North America: Food Animal Practice 8, 559-573.

Touchette KJ, Allee GL, Newcomb MD and Boyd RD 1998. The lysine requirement of lactating primiparous sows. Journal of Animal Science 76, 1091-1097.

Trottier NL, Johnson LJ and de Lange CFM 2014. Applied amino acids and energy feeding of sows. In The gestating and lactating sow (ed. C Farmer), pp. 117-140. Wageningen Academic Publishers, Wageningen, The Netherlands.

Vallet JL, Miles JR and Rempel LA 2013. Effect of creatine supplementation during the last week of gestation on birth intervals, stillbirth, and preweaning mortality in pigs. Journal of Animal Science 91, 2122-2132.

van Dijk AJ, van Rens B, van der Lende T and Taverne MAM 2005. Factors affecting duration of the expulsive stage of parturition and piglet birth intervals in sows with uncomplicated, spontaneous farrowings. Theriogenology 64, 1573-1590.

van den Bosch M, Wijnen J, van de Linde IB, van Wesel AAM, Melchior D, Kemp $B$, van den Brand $H$ and Clouard C 2019. Effects of maternal dietary nitrate supplementation on farrowing and placental characteristics, level of asphyxiation at birth and piglet vitality. Theriogenology 129, 1-7.

Xu Y, Zeng Z, Xu X, Tian Q, Ma X, Long S, Piao M, Cheng Z and Piao X 2017. Effects of the standardized ileal digestible valine:lysine ratio on performance, milk composition and plasma indices of lactating sows. Animal Science Journal 88, 1082-1092.

Xue L, Piao X, Li D, Li P, Zhang R, Kim S and Dong B 2012. The effect of the ratio of standardized ileal digestible lysine to metabolizable energy on growth performance, blood metabolites and hormones of lactating sows. Journal of Animal Science and Biotechnology 3, 11.

Yang H, Pettigrew JE, Johnston LJ, Shurson GC and Walker RD 2000. Lactational and subsequent reproductive responses of lactating sows to dietary lysine (protein) concentration. Journal of Animal Science 78, 348-357.

Young MG, Tokach MD, Aherne FX, Main RG, Dritz SS, Goodband RD and Nelssen JL 2004. Comparison of three methods of feeding sows in gestation and the subsequent effects on lactation performance. Journal of Animal Science 82, 3058-3070. 